by analogy I am prepared to find that the callosities are very rarely transmitted to the offspring. Definite knowledge on the subject would certainly elucidate the argument.

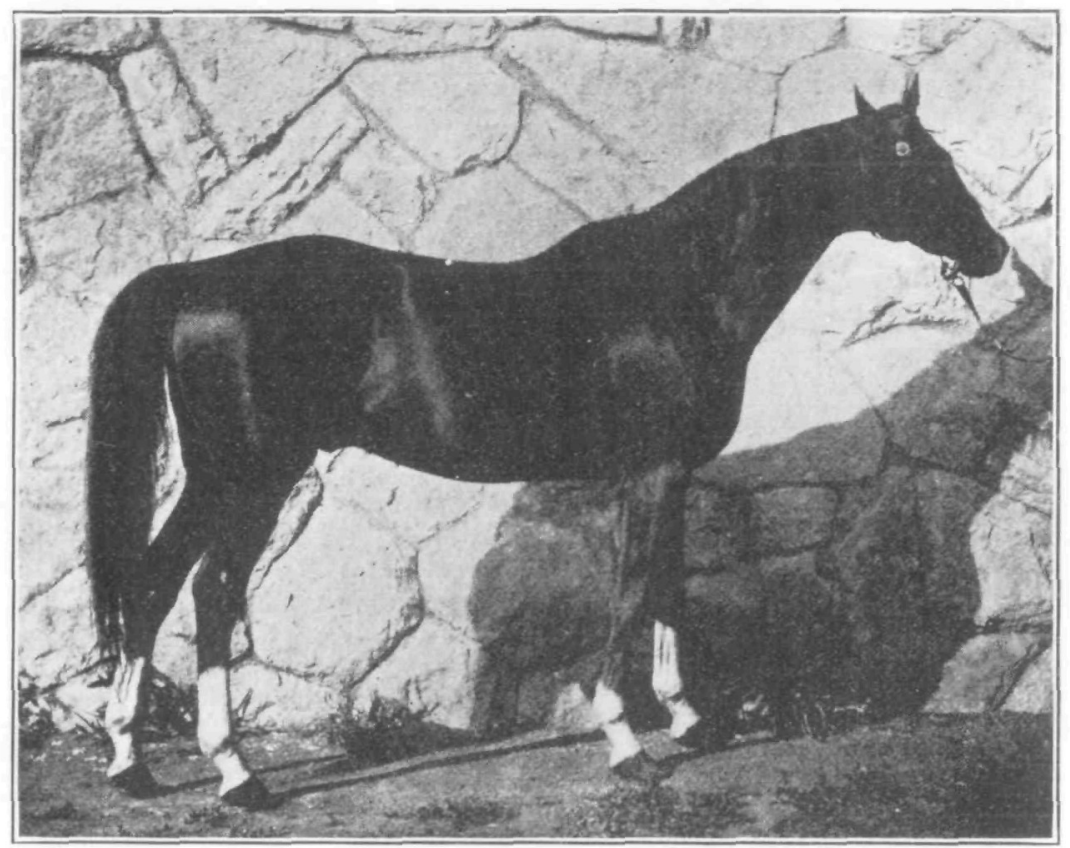

Fig. 13.-8nitaton.

Imported Thoroughbred, ahowing Fozarth's line of beauty in neck.

[oontinuation in next number]

\title{
THE AGE FACTOR IN REGISTER-OF-MERIT JERSEYS
}

E. N. Wentwoeth

\author{
Ioroa State College, Ames, Ioroa
}

Some time ago, in connection with the various factors that influence maturity in animals, the age of parents at time of conception came under discussion. While there is little or no experimental evidence with respect to animals, yet the common practices of plant breeders in developing plants in more rigorous climates evoked the belief that youth in either parent at time of conception might modify the matu- 


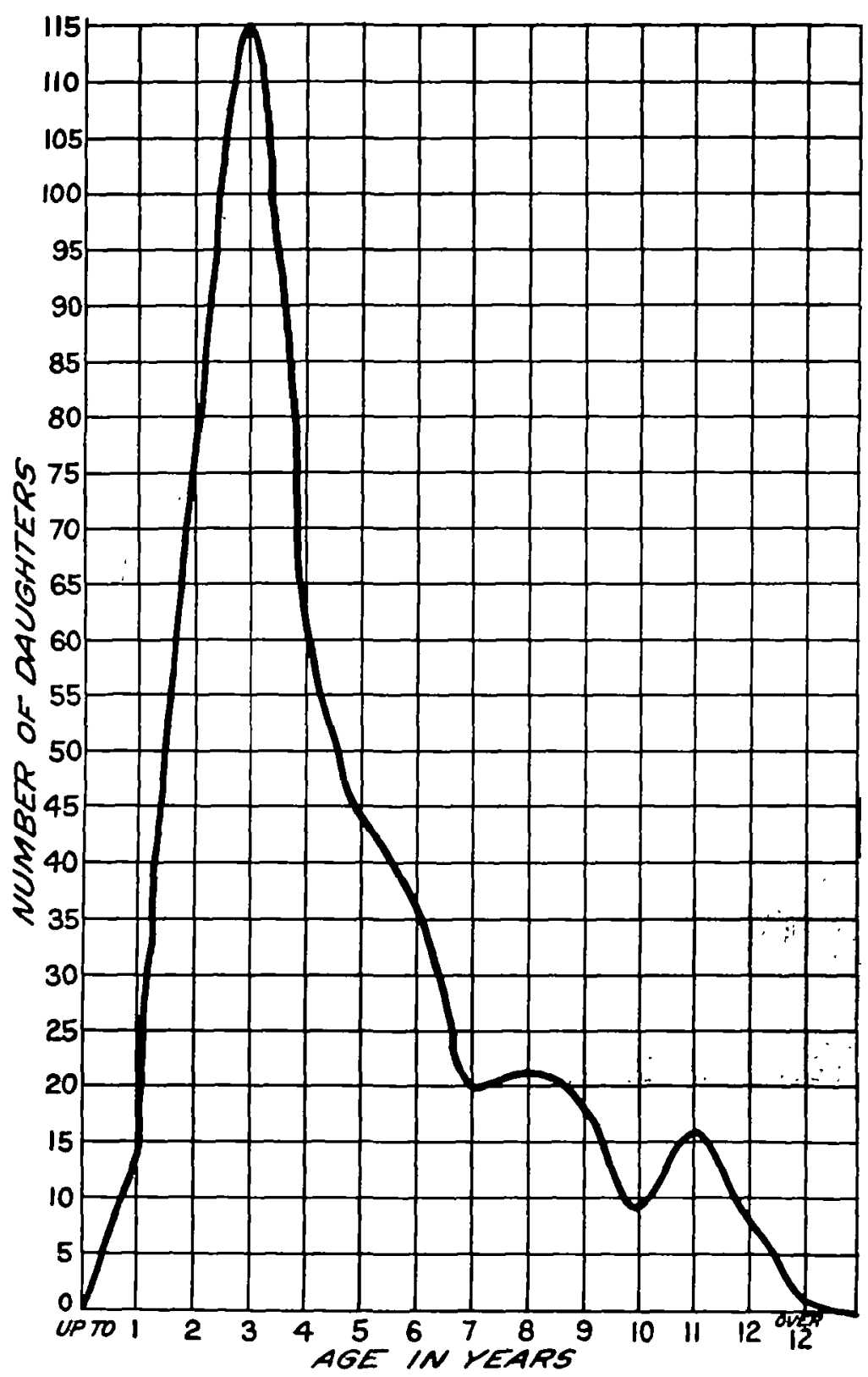

Fia. 1.-Age or Sire ne Relation to Numen or Dafahteses. 
rity factor. With this idea in mind an examination of Jersey cows in the Register of Merit with reference to their sire's age was conducted and the curve in Fig. 1 plotted.

The result, to say the least, was surprising. While many breeders follow the practice of developing young bulls, yet it was surprising to discover that such a large percentage of the animals of the breed were the offspring of young animals. As can be plainly seen, 46.8 per cent of the animals were sired by bulls under three years of age, or nearly half of the number studied. In explanation of this it

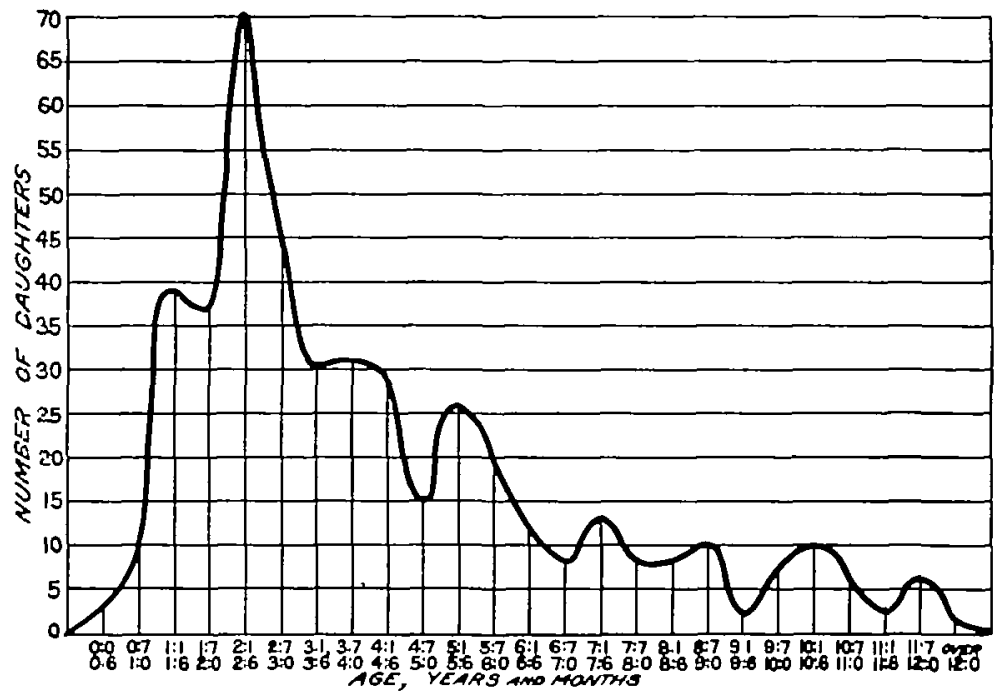

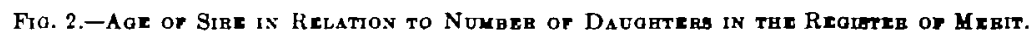

has been said that breeders try a young bull and then sell him to men that do not put their females in the Register of Merit. While this may account for part it does not seem that all animals are thus answered for.

In order to study the distribution more thoroughly a second curve was plotted using a half year for the age unit rather than one year. This curve shows that 16 per cent of the total sires of the breed are from two years one month to two years six months old at time of service; 10.3 per cent are from two years seven months to three years. This is shown in curve, Fig. 2.

In order to compare the age of the sire with the age of his daughters at the time these made their record (the only index for maturity and that not absolutely satisfactory) a table was compiled which brought 
to light an interesting fact. The average age of sires is four years and six months and the average age of daughters at time of record is the same. However, viewing this from the standpoint of the correlation coefficient the relation between variations in age is only casual, as a coefficient of \pm 0.5269 is not high enough to suggest any marked relation. One factor which may modify this and which perhaps if omitted from figuring might produce a closer correspondence, is the fact that a bull comes to service at a much younger age than a cow comes to milking power. If these thirty-eight young bulls were left out, a much larger coefficient could be established. Another peculiar fact is that the modal age is the same, for both sire and daughter or, in other words, the typical age, $2-2 \frac{1}{2}$ years, is the same both for service and for record making.

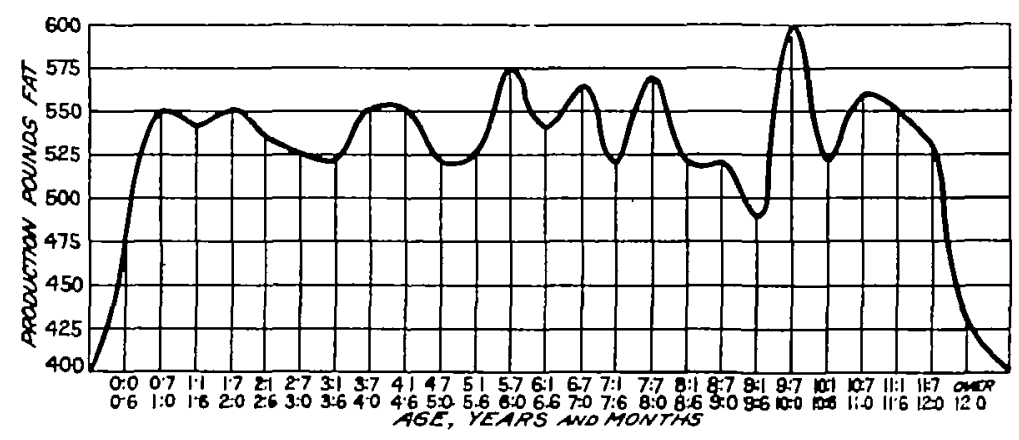

Fra. 3.-Relation or Aar or gine to Phoddction or Daughten.

The relation of age of sire to production of cow was tabulated, and a higher coefficient of correlation \pm 0.6647 was found. The curve plotted from the table, however, shows very little of value, as only in the center of the curve is there found a strong tendency to positive correlation, a gradual increase in the curve (see fig. 3 ) in the younger ages being more than offset by a decrease in highest ages.

Next in order a table was compiled in which the production of the cows was all put on the same basis. Week records were discarded and only the year records and the three months records at St. Louis were considered. These latter were assumed to equal about two-fifths of the year's production, while the former were all put on a similar basis (that of the mature cow) from the standpoint of age. For example Brown Lassie's Prize 192584 made a record of 325 pounds 8.8 ounces, beginning at two years and two months old. The advanced registry requirement for that age is 250 pounds of butter- 
fat in a year, while the requirement for a cow five years old or over (mature) is 400 pounds of butterfat. This difference in requirement is due to the increased capability of the cow as a producer when she matures. Then a record of 325 pounds of fat at two years two months is greater than the same record at five. To put these on a similar basis, direct proportion by means of the standards fixed by the American Jersey Cattle Club were used. Under this condition 325 pounds 8.8 ounces of fat in the "under thirty months" form equals 500 pounds 13 .ounces in the mature form. Putting all records on this basis, the average production of all of the Jersey cows in the Register of Merit is 526 pounds 8 ounces.

Table 1 shows some interesting figures derived from this work. The sires have been divided equally into three groups, dividing the range of age into thirds, rather than grouping into equal numbers of sires. In only one case does the oldest group of sires lose anything to the younger, in spite of the larger number of younger animals. In average production the middle and younger sires have the advantage. In number of performers above the average in each group, and in relative early maturity of daughters, the younger and middle aged sires must yield to the older; as compore 523 pounds 7 ounces and 530 pounds 2 ounces with 513 pounds 15 ounces. In the case of maturity this is directly opposite to our plant breeder's experience. However, the relatively small number of old sires introduces a greater probable error, so great as to leave doubt in the mind as to the value of drawing conclusions.

In the course of the work one or two interesting facts came to light which are partial remuneration for the negative results of the preceding work. In the majority of cases there is a direct correlation between the high lactation period of the cow and the merit of calf which preceded this period. Presumably, however, this difference lies in the superabundance of vital force the cow possessed at this time and the energy thus transferred to the offspring.

Another fact which came out was the relatively large number of bulls which seemed to sire most of their Register of Merit daughters within one season. One can scarcely claim that the point needs explanation other than the ordinary factors of buying, selling, advertising, and the succession of a new bull as head of a herd of productive cows; yet the point is worthy of note, as it may be that in our highly artificially bred domestic cattle the greatest efficiency of reproduction is a sadly limited period. 
TABLE 1.-Three age-groups of sires with average production and age of respective oroups of daughters.

\begin{tabular}{|c|c|c|c|c|c|}
\hline \multirow[b]{2}{*}{ Azo of mire. } & \multicolumn{5}{|c|}{ Daughters. } \\
\hline & $\begin{array}{c}\text { Total } \\
\text { number. }\end{array}$ & $\begin{array}{l}\text { Number } \\
\text { abovo } \\
\text { ererage. }\end{array}$ & $\begin{array}{l}\text { Per cent } \\
\text { abore } \\
\text { averago. }\end{array}$ & $\begin{array}{l}\text { Average } \\
\text { 1ndividual } \\
\text { prodaction. }\end{array}$ & $\begin{array}{l}\text { Agro at time } \\
\text { of record. }\end{array}$ \\
\hline yrs.mo.yrs.mo. & & & per cont & lbs. ase. & vro. mos. \\
\hline $\begin{array}{l}0: 0-0: 0 \\
0: 7-1: 0\end{array}$ & $\begin{array}{l}3 \\
\theta\end{array}$ & $\begin{array}{l}0 \\
4\end{array}$ & $\begin{array}{r}0.00 \\
44.44\end{array}$ & $\begin{array}{l}\mathbf{4 1}: 1 \\
\mathbf{5 3 2}: 11\end{array}$ & $\begin{array}{l}5: 5 \\
4: 24\end{array}$ \\
\hline $1: 1-1: 0$ & 28 & 10 & 38.46 & $640: B$ & $4: 78$ \\
\hline $1: 7-2: 0$ & 27 & 15 & 0.5 .55 & $533: 5$ & $4 \therefore 1$ \\
\hline $2: 1-2: 6$ & 54 & 21 & 38.88 & $519: 0$ & $1: 2.5$ \\
\hline $3: 7-3: 0$ & 31 & $\theta$ & 20.03 & $507: 1$ & $4: 9$ \\
\hline $3: 1-8: 6$ & 28 & $\mathbf{8}$ & 30.77 & $609: 14.4$ & $4: 4$ \\
\hline $3: 7-4: 0$ & 23 & 11 & 47.83 & $530: 155$ & $6:$ if \\
\hline Averager........ & $\ldots \therefore \ldots$ & 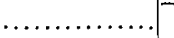 & 39.2 & $523: 7$ & $4: 7.4$ \\
\hline Probsble error.. & 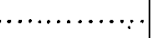 & & +090 & $\ldots \ldots$ & $\ldots \ldots \ldots$ \\
\hline $4: 1-4: 6$ & 13 & 11 & 47.83 & $540: 04$ & $8: 0$ \\
\hline $4: 7-5: 0$ & 15 & s & 33.83 & $503: 10$ & $4: 2$ \\
\hline$B: 1-5: 6$ & $1 \theta$ & 8 & 42.11 & $610: 14.5$ & $4: 8$ \\
\hline $5: 7-6: 0$ & 16 & 0 & 56.25 & $800: 8$ & $4: 10$ \\
\hline $0.1-6: 0$ & 8 & 4 & 8000 & $530: 3$ & $4: 75$ \\
\hline $6: 7-7: 0$ & 8 & 5 & 69.50 & $549: 7.5$ & $s: 10$ \\
\hline $7: 1-7: 0$ & 12 & 3 & 2800 & $608: 5$ & $4: 2$ \\
\hline $7: 7-8: 0$ & $\theta$ & 4 & 06.66 & $560: 0$ & $5: 7$ \\
\hline Averago $\ldots$. & 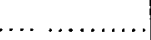 & & 45.80 & $830: 2$ & $4: 0.3$ \\
\hline Probable error.. & & & +2.78 & $\ldots \ldots$ & $\ldots \ldots \ldots$ \\
\hline $8: 1-8: 6$ & 7 & 2 & 28.57 & $514: 4.8$ & $3: 1 \frac{5}{7}$ \\
\hline $8: 7-0: 0$ & 7 & 2 & 2867 & $502: 12$ & $: 5$ \\
\hline $0: 1-0: 6$ & 2 & 1 & 5400 & $400: 15$ & : 8.6 \\
\hline $9: 7-10: 0$ & s & 4 & 80.00 & $450: 4$ & $4: 4.6$ \\
\hline $10: 1-10: 0$ & 10 & 8 & 8000 & $511: 127$ & $3: 6.5$ \\
\hline $10: 7-11: 0$ & 7 & 5 & 7143 & $502: 38$ & $4: 1$ \\
\hline $11: 1-11: 0$ & 2 & 1 & 8000 & $536: 12$ & $8: 65$ \\
\hline $11: 7-19: 0$ & 0 & 4 & 00.60 & $522: 3$ & $4: 4.6$ \\
\hline over $12: 1$ & 1 & 0 & 00.00 & 112:0 & $2: 0$ \\
\hline $\begin{array}{l}\text { A varage ........... } \\
\text { Probablo error... }\end{array}$ &... & & $\begin{array}{c}40.8 \\
+5.70\end{array}$ & $513: 16$ & $1: 117$ \\
\hline Total......... & 853 & 140 & 42.21 & $\ldots \ldots$ & ........ \\
\hline
\end{tabular}

Another interesting point lay in the relative influence in inheritance between the bull and the cow in the production of sons capable of siring Register of Merit daughters. Without transposing the records to the basis of the above work, a coefficient between the sire and son of 0.821 existed, while the transposed records gave a relationship of 0.862. Taking the latter relationship with the cow the coefficient 0.727 was derived. This would show a slightly stronger influence for the bull, but as the number of cases was smaller with the cows the 
probable error would be enough larger to nearly neutralize this difference. This should set at rest the minds of many dairymen who believe that a dairy bull from a high performing cow is of more value as a sire than a bull whose daughters have proven worthy of registry. It furthermore brings a closer harmony with the theory of the equal potency of parents, something which practical men have hesitated to accept.

In conclusion it may be said that deductions from this work are practically impossible. While the introductory curves are somewhat surprising, a detailed study fails to show a strong correlation between any age of sire and maturity or production of the offspring. The premises may not be correctly taken, but it seems to the writer they are nearly enough so, to assure him of the lack of age as a factor in the conditions studied.

\title{
YIELD TESTS AS A BASIS OF AW ARDING PRIZES AT CORN SHOWS
}

\author{
G. N. Collins \\ Department of Agriculture, Washington, D. C.
}

The corn show has without doubt been an important factor in the development of interest in our principal crop. Competition is a powerful incentive, and encourages attention to details and minor differences that would be overlooked without this stimulus. In fostering competition, however, care should be taken that the competition is making in the direction of real improvement.

The avowed object in awarding prizes in corn contests is to give credit to the best exhibit of corn, that is, the exhibit of corn which it would be most profitable to grow ${ }^{1}$ a worthy object which it would seem should eliminate from a score card any character not correlated with high performance.

At the time that score card methods were applied to corn judging, almost rothing was known regarding those characters of the ear which are associated with high yield. In the absence of experimental data the choice of points would seem to have been based on the idea that the size of the cob was fixed and the best ear was the one that approached the nearest to the maximum amount of grain that could

\footnotetext{
1 Seo Bowmen and Craseley, Corn, p. 406, and Ohlo Afrbultural Experiment Station Creulars Noa. 43, 61, eto.
} 